\title{
Us Mob Online: The Perils of Identifying as Indigenous on Social Media
}

\author{
Bronwyn Carlson * (D) and Tristan Kennedy (D)
}

Department of Indigenous Studies, Macquarie University, Sydney, NSW 2109, Australia; Tristan.kennedy@mq.edu.au

* Correspondence: bronwyn.carlson@mq.edu.au

\begin{abstract}
Social media is a highly valuable site for Indigenous people to express their identities and to engage with other Indigenous people, events, conversations, and debates. While the role of social media for Indigenous peoples is highly valued for public articulations of identity, it is not without peril. Drawing on the authors' recent mixed-methods research in Australian Indigenous communities, this paper presents an insight into Indigenous peoples' experiences of cultivating individual and collective identities on social media platforms. The findings suggest that Indigenous peoples are well aware of the intricacies of navigating a digital environment that exhibits persistent colonial attempts at the subjugation of Indigenous identities. We conclude that, while social media remains perilous, Indigenous people are harnessing online platforms for their own ends, for the reinforcement of selfhood, for identifying and being identified and, as a vehicle for humour and subversion.
\end{abstract}

Keywords: Aboriginal; Indigenous; social media; identity; hate speech; community; online

check for updates

Citation: Carlson, Bronwyn, and Tristan Kennedy. 2021. Us Mob Online: The Perils of Identifying as Indigenous on Social Media. Genealogy 5: 52. https://doi.org/ 10.3390/genealogy5020052

Received: 14 April 2021

Accepted: 19 May 2021

Published: 24 May 2021

Publisher's Note: MDPI stays neutral with regard to jurisdictional claims in published maps and institutional affiliations.

Copyright: (c) 2021 by the authors. Licensee MDPI, Basel, Switzerland. This article is an open access article distributed under the terms and conditions of the Creative Commons Attribution (CC BY) license (https:// creativecommons.org/licenses/by/ $4.0 /)$.

\section{Introduction}

For as long as social media platforms have existed, the topic of Indigenous identity has featured in online conversations and debates. Research reveals that for Indigenous people, identifying as Indigenous online is a risky business where you are likely to be subjected to extreme hate and racism (see, Carlson 2016; Carlson and Frazer 2018a, 2018b; Kennedy 2020). Social media is also a popular vehicle amongst Indigenous people used to express their identities and to engage with other Indigenous people, events, and conversations. Social media has made possible connections across vast distances and with other Indigenous people across the globe. The ability for Indigenous people to connect en masse is unprecedented- "we are finally present online in ways that the mainstream is unable to disavow" (Brock 2020, p. 1).

From the early days of social media Indigenous people were creating pages and sites to publicly express their pride in being Aboriginal. In one example, the founder of IndigenousX (an Indigenous-led media organisation that includes a rotating Twitter account where a different Indigenous person manages the handle for the week. It also includes a weekly op-ed. See, https:/ /indigenousx.com.au, 29 May 2013), Gamilaroi man Luke Pearson tweeted:

There is a FB page called "I am proud to be Aboriginal" that has over 10k likestake that, FB trolls:-). (@IndigenousXLtd, posted, 29 May 2013)

Indigenous people are harnessing the affordances of digital technologies to express their identities and their collective survival of colonialism. Thus, social media platforms play a significant role in public articulations of identity. Pride in being Indigenous is displayed through a range of interactions including with specific pages like "I am proud to be Aboriginal". Pride is also displayed via profile pics, cover photos, followers and followees, tweets, retweets, posts, and handles. Public assertions of Indigenous identities, 
such as through the commonly used hashtag \#StillHere demonstrates, are also about reclaiming identities that have been impacted by colonialism. Native American scholars Taiaiake Alfred and Jeff Corntassel argue that it is important for Indigenous people to "identify all of the old and new faces of colonialism that continue to distort and dehumanize Indigenous peoples-often pitting us against each other in battles over authentic histories" (Alfred and Corntassel 2005, p. 601). They also remind us that "there is a danger in allowing colonization to be the only story of Indigenous lives" (p. 601).

Being Indigenous is political. This is exemplified in many social media profiles and Twitter handles, particularly those of Aboriginal activists. For example, community organiser for 'Warriors of the Aboriginal Resistance (WAR) (see, DeWitt 2015), Tarneen Onus Williams' Twitter handle is, "assigned blak at birth". Similarly, Yuin scholar Marlene Longbottom's Twitter handle is "Hon member of the Far Black". Indigenous people are using digital platforms to tell the story of Indigenous lives, to be publicly visible, and to resist and reject colonial notions of what it means to be Indigenous. "Being Indigenous" according to Alfred and Corntassel (2005) then, "means thinking, speaking and acting with the conscious intent of regenerating one's indigeneity" (p. 614). "The only thing that has got us anything is Black resistance" tweeted Munanjahli and South Sea Islander scholar Chelsea Watego (posted, 25 January 2021). Indigenous people in Australia often use the term 'Blak' or 'Black' to reference themselves. These terms do not necessarily refer to one's skin colour. They are used to denote one's Indigenous identity (see, Liddle 2014).

Despite the positive potential, openly identifying as Indigenous or asserting pride in Indigeneity online risks less liberating outcomes such as questions about whether one is "really Indigenous" or various other forms of racism and harassment from nonIndigenous people. One of the most persistent accusations that Indigenous people deal with in everyday life and on digital platforms, is from non-Indigenous people asserting that they do not "look" Indigenous. Such accusations speak to the lack of understanding about Indigenous people and their relationship to others and assume there is a "look" that determines one's Indigenous status. Arrernte feminist Celeste Liddle tweeted in response to this notion:

It doesn't matter how dark or fair we are, we're not a fucking spectacle for tweeps to analyse and take apart at their leisure. We don't exist for you. We exist for mob, for community and they're the ones who get to judge where we fit in, not random tweeps. (@Utopiana tweeted 30 October 2020)

Indigenous people tire of endlessly answering posts and comments that question their Indigeneity based on categories such as skin colour, blood quantum, and disadvantage. Indigenous people will routinely seek out ways to find humour in many of these situations. Humour is a great survival mechanism as noted by Bidjara/Pitjara, Birri Gubba and Juru author Jackie Huggins who argues "Black humour is often so delicate that it is hard to locate, and Europeans come off with a baffled feeling without knowing quite why" (Huggins cited in Duncan 2014, p. 1). She goes on to explain that Aboriginal people "draw humour from situations and definitions about them which would prove painful and offensive if told by Europeans" (cited in Duncan 2014, p. 1). In this post an Aboriginal person was responding to being asked if they are a "full-blood" Aboriginal person-an offensive term based on colonial ideology:

Are you full-blood Aboriginal?

Yeah my dads Ernie Dingo and my mum is a roll of Devon [laughing emojis]. (post shared on the Facebook page The Yarning Circle, 18 October 2020)

Justifying your existence is wearisome. Humour is a defensive strategy to survive the onslaught. Questions relating to blood quantum remain common as the post above illustrates. In response to the question by a non-Indigenous person asking them if they are "full-blood", the Aboriginal person deploys humour as a defensive strategy. Ernie Dingo is a well-known Aboriginal television presenter and quite possibly the only Indigenous person some people would know or recognise on mainstream television. Devon is a 
manufactured meat product popular in Australia and is something that many Indigenous people enjoy because it is relatively cheap.

In this article, we present the standpoints of our research participants and other notable Indigenous people regarding the perils of identifying online. We discuss the debates surrounding identity as these play out in the public sphere and we note the legal identifiers used by colonial governments to 'establish' who Indigenous people are. In addition, this article outlines some of the ways that harmful content on social media is interpreted and experienced by Indigenous peoples and how this content can be seen to reflect colonial ideologies surrounding Indigenous identity. This article identifies an urgent need for a mature re-evaluation of identity politics in Australia and across the globe in an emerging and fast-paced era of global digital citizenship.

\section{Methodology}

This article draws on data collected as part of two national studies. Firstly Carlson's national research project was funded by an Australian Research Council Discovery Indigenous grant. The purpose was to gain a better understanding of how social media is entangled in the production and expression of Aboriginal identities and communities. Secondly, Kennedy's investigation, funded by Facebook Australia, into Indigenous peoples' experiences of negative and harmful content on social media platforms was aimed at identifying and naming specific experiences of negativity from culturally nuanced perspectives of Indigenous Australians.

Data was collected using a mixed-methods approach which deployed in-depth interviews and online social media-driven surveys. Participants in both studies represented a large age range (18-60 years of age) and various social and cultural backgrounds. In Carlson's study ten Indigenous communities across New South Wales, Queensland, South Australia, Tasmania, and Western Australia were included in the project. Over 60 semistructured interviews were conducted. Carlson also collected data through an online social media-driven survey created using SurveyMonkey and promoted via Facebook and Twitter $(n=75)$. Respondents to the online survey were from every State and Territory. In Kennedy's study participants represented Indigenous communities across Queensland, New South Wales, South Australia, and Western Australia. In total, three semi-structured interviews and three focus groups (four participants each) were conducted via digital communication software (Zoom). Kennedy's online quantitative survey received over 50 responses from Indigenous peoples across Australia.

The emergence of Indigenous research methodological frameworks has provided strong critiques of dominant Western-centric social analysis (Martin 2008; Moreton-Robinson 2013; Nakata 2007; Rigney 1997; Smith 2012). Following this critique, our analysis is guided by Torres Strait Islander scholar Martin Nakata's idea of the 'Cultural Interface' - a concept he developed to denote the everyday site of struggle that continues to envelop colonised peoples. For Nakata, the Cultural Interface represents a site of interaction, negotiation, and resistance whereby the everyday articulations of Indigenous people can be understood as both productive and constraining (Nakata 2007). It is a space where agency can be effected, where change can occur, where Indigenous people can 'make decisions'.

As both a symbolic and material site of struggle, understanding the Cultural Interface allows the scholarly exploration of everyday Indigenous experience. It encourages researchers to see that, as Nakata explains:

there are spaces where people operate on a daily basis making choices according to the particular constraints and possibilities of the moment. People act in these spaces, drawing on their own understandings of what is emerging all around them ... in this process, people are constantly producing new ways of understanding and at the same time filtering out elements of all those ways of understanding that prevents them from making sense at a particular point in time and trying in the process to preserve a particular sense of self. (Nakata 2007, p. 201) 
The Cultural Interface is a particularly apposite mode of analysis for our research. On the one hand, it encourages us to see social media as always already mediated by existing Indigenous-settler relations of colonial violence. Additionally, the Cultural Interface also permits a space for possibility in which these mediated relations can always be challenged and dismantled.

\section{Being Indigenous Online}

Early research suggested that being online provided a disembodied space where subjects can shift and change and be creative in terms of the identity displayed (Robins 1995; Bell and Kennedy 2000; McCormick and Leonard 1996). Anonymity was part of the attraction-one can be whoever they desire online even if this was significantly different from one's offline reality. As Shapiro suggests, a key affordance of anonymity on the Internet is the ability to engage in 'identity work' (Shapiro 2015, p. 124). That is, the ability to work at a variable, or fractured, presentation of one's identity which may or may not align with individual corporeality. This fracturing of identity was succinctly captured in a cartoon by artist Peter Steiner published in 1993 by the New Yorker which features a dog sitting at a computer telling his canine companion that "on the internet nobody knows you are a dog"' (Sardá et al. 2019, p. 558). For Indigenous people, however, this freedom to safely engage in identity work has not generally been the case. Even in the rare early studies that focussed on Indigenous people and the Internet, it was evident that Indigenous people did not attempt to disembody their Indigeneity online. For example, in his study of Inuit identities online Neil Christensen found that the Inuit "are generally embedding offline life into cyberspace" and that "[t]he Internet is not necessarily a space to hide in, nor is it a space that mysteriously filters away the cultural identity of people" (Christensen 2003, p. 23).

Research clearly demonstrates that Indigenous people embody rather than disembody their identity when interacting online and particularly on social media (Lumby 2010; Carlson 2016). Online identities are the product of cultural practices by real social agents that, while not inhabiting the same spatio-temporal domain, are still very much subject to scrutiny and regulations as they are in face-to-face interactions. It is the case, in many instances, that social media communication translates into the domain of subjectivity outside of online contexts. For example, 'friends' and 'followers' on social media invite others to attend events and actively engage in conversations. Furthermore, many Indigenous users post pictures of themselves and others attending events to demonstrate their involvement with and support for specific activities. This is particularly popular in relation to activist events and attending protests such as 'Black Lives Matter', 'Stop Aboriginal deaths in custody', or 'Abolish Australia Day'.

This is not to suggest that Indigenous people do not engage in embellishment or creativity in the way they fashion their profiles. We are sure that many do. Our research has identified cases where Indigenous social media users feel the need to overly 'Indigenise' their profile. There are instances where anxiety is expressed when profiles do not demonstrate Indigeneity at first glance (Lumby 2010; Carlson 2013). We asked people about their profiles and whether they have ever made conscious efforts to ensure their Indigeneity was obvious. One participant stated: "Yes because I have fair skin, I have had people say I am not really Aboriginal". Another commented that they actively engage in online conversations on Indigenous issues and make an effort to relay an Indigenous identity: "Looking at my physical features most people say I look South American or Irish. I have that I work at the Aboriginal Medical Service. I like and share Aboriginal pages and posts. I share my political opinions on Indigenous matters".

Indigenous interaction online often mirrors or adheres to offline expectations and demands. In contemporary Australia, Indigenous identity is not a straightforward affair (see, Carlson 2016). There is much debate that circulates in the "whitestream" media (Johnson 2011, p. 104), in academia, and community spaces (both online and offline) about who counts or should count as Aboriginal or Torres Strait Islander and, who could or 
should confirm such claims (Noble 1996; Oxenham et al. 1999; Huggins 2003; Paradies 2006; Bond 2007; Heiss 2007; Lamb 2007; Ganter 2008; Gorringe et al. 2011; Carlson 2016).

\section{Identity Debates}

Questions around Indigenous identity are not new. As one of the participants was reflecting on their experience of identifying as Aboriginal on social media, they commented: "if they know you are Aboriginal or support Aboriginal things you will cop it". Another participant spoke about making posts that speak up against discrimination directed at Indigenous people: "if you were as pale as I am, you didn't speak about your Indigenous side. Because when you didn't look the part, you got endless questions, so I have carried that through my adult life. I tend not to show or represent my Indigenous side because I don't want the whole conflict of but you're not".

There are some non-Indigenous people who have built their political or media careers on the topic. One Nation political party leader Pauline Hanson and right-wing media commentator Andrew Bolt are two examples that were routinely pinpointed by participants. As one participant noted: "I haven't seen [references to] Hanson so much as in the last week because of Black and white friends of mine sharing what went on". Participants suggested that the combination of mainstream media offering a platform to the likes of Hanson and Bolt with the ability to quickly share and spread these stories across social media means that this questioning of Indigenous identity and the racist vitriol that often follows is experienced routinely by Indigenous peoples.

Hanson has, throughout her political career, and in an effort to bring about social and political division, asserted that Aboriginal people receive more financial benefits than other Australians. She was interviewed in 2016 by Bolt on his program, the 'Bolt Report' to discuss the issue of Indigenous identity. Hanson asked, "what defines an Aboriginal?", claiming there is no definition and implying that anyone can claim to be Aboriginal in order to receive extra welfare benefits. In response to Hanson's comments, Ryan Griffen, the creator of the television series 'Cleverman', an Indigenous Australian superhero series, took to Twitter tweeting: "Another white person telling us what it means to be Aboriginal. It don't work like that". He then encouraged other Twitter users to share their experiences using the hashtag \#DefineAboriginal. Of the many responses, one person tweeted: "We are here, we are proud \& we are strong [fist emoji] \#DefineAboriginal" (Tweeted 29 November 2016).

Bolt too has a history of questioning Indigenous identity. In 2009, he published a series of columns targeting Indigenous people. In one article which he titled, White is the New Black (Bolt 2009), he took issue with the success of Aboriginal people who he describes as being of 'light-skin' and that 'choose' to be Aboriginal when they could have chosen any one of a number of non-Aboriginal heritages. Bolt was implying that there are people of Aboriginal descent who should not count as Aboriginal or be able to claim to be Aboriginal. At the heart of his allegations was his logic that such 'choices' were either motivated by an ensuing public or professional elevation that would not otherwise have been accorded and private rewards that would not otherwise have been achieved on talent alone. Nine of those targeted by Bolt brought a case against him under the Racial Discrimination Racial Discrimination Act (1975) and he was found guilty. Bolt's defence for this court case was mounted on freedom of speech but the litigants argued that at a more fundamental level the case was about who has the right to define Aboriginal identity.

Interestingly, both Bolt and Hanson have made public assertions that they themselves are 'Indigenous' - each claiming that they were born in Australia and are, therefore, 'Indigenous' (see, Mansell 2014). In 2019, Hanson again made the headlines when she confronted a group of young Indigenous women asserting that she too was Indigenous (see, Yahoo News 2019). Hanson stated, "I'm Indigenous, I was born here, I'm native to the land. So, you know, I'm Australian as well, and I'm Indigenous". Hanson went on to beleaguer the young women stating, "Do you know the word Indigenous? It means native to the land, I was born here. Where's my land if not Australia?". In what quickly became a laughable 
moment for Indigenous people on social media, one of the young women responded by telling Hanson that her land was "um, England".

Such unsolicited and misinformed accusations have become a ritual and a pastime for members of the One Nation political party. Party member Mark Latham also made news headlines after he too joined their bandwagon and raised questions about Indigenous identity. Similar to Hanson, he claims:

Australians are sick and tired of seeing people with blonde hair and blue eyes declaring themselves to be Indigenous, when clearly, they have no recognisable Aboriginal background and are doing it solely to qualify for extra money. (Han 2019)

Latham's assertions are built on the idea that Indigenous people receive extra funding not available to other Australians because they claim to be Indigenous. Like Bolt, his logic lies in the argument that if you don't 'look' Aboriginal you should aspire to be 'Australian' as opposed to being Indigenous. Characterisations of Indigenous Australians as recipients of a "free ride" and who are seen to be motivated to rort the public purse have their roots in an ignorance (and at times an active denial) of Indigenous experiences of dispossession, colonization, and ongoing colonial violence (see, Carlson 2020). This ignorance originates from the ideology embedded in the colonial assimilationist project, which specifically focuses on Indigenous people who were considered of "mixed" heritage. For example, the Western Australian Chief Protector, A.O. Neville developed a plan to assimilate Aboriginal people into Australian society. The goal was to 'breed out' the skin colour from Aboriginal people to reach the goal of a White Australia (Carlson 2016). Those deemed 'full blood' would, it was hoped, die out. Those identified as 'half-castes' would be removed and institutionalised away from families. Controlling marriages among 'halfcastes' and particularly women and 'encouraging' intermarriage with the lower classes of white men was also part of the strategy. In this way, it would be possible, according to Neville, to "eventually forget that there were ever any Aborigines in Australia" (Neville cited in Manne 2010) In contrast to the likes of Neville, anthropologist W.E.H. Stanner posed in 1958 that:

[a]ssimilation means that the Aborigines must lose their identity, cease to be themselves, become as we are. Let us leave aside the question that they may not want to, and the possibility-I would myself put it far higher than a possibilitythat very determined forces of opposition will appear. Suppose they do not know how to cease being themselves? (Stanner 1979, p. 50)

Despite the horrendous efforts of the colonial project, Indigenous people, for the most part, have been able to resist and continue to identify as Indigenous regardless of their appearance. This was articulated by one of our participants who stated: "I am no less black because I inhabit this skin". For this individual, as for all participants, the colonial project was irrefutably unsuccessful in erasing their Indigenous identity.

\section{Working Definition}

Contrary to assertions by Hanson and Bolt, there is a multitude of definitions of Indigenous identity in Australia as exemplified by John McCorquodale $(1986,1997)$. McCorquodale provided a history of legislative definitions of Aboriginal people in Australia finding 67 definitions that classified Aboriginal people in 700 pieces of legislation. Since the 1970s there has been a definition of Indigenous status which was introduced by governments and largely accepted by Indigenous individuals and community groups (Boladeras 2002; Carlson 2016). Aboriginal and Torres Strait Islander people have, however, always had their own knowledge of identity in terms of their relationships to other humans, more-than-humans, and to Country. As expressed by Durrumbal, Killilli, and Yidinji social worker Tileah Drahm-Butler: "identity is our strong story" (2015). It is not uncommon for Indigenous people to establish a connection with each other by asking about such relationships. As Kalkadoon and Bandjin narrative practitioner Justin Butler asserts: "This 
telling of our identity goes back into distant history, before colonisation. However, we also acknowledge that, for many, this story has been stolen" (Butler 2017, p. 23). Colonisation has certainly impacted Indigenous relationality and determining who is Indigenous in the aftermath of so many violent colonial policies and practices have at times been a difficult task.

A three-part assessment was introduced by the government as a means to identify Indigenous people for the purposes of administering resources and funding in an attempt to address the inequality as a result of targeted policies that have left a legacy of trauma and social and economic disadvantage. In the government's definition, a person can be accepted if they are "a person of Aboriginal or Torres Strait Islander descent and who identifies as an Aboriginal or Torres Strait Islander and is accepted as such by the community in which he (she) lives" (Gardiner-Garden 2002-2003, p. 4). Proof of acceptance by the community requires a supporting letter from an Aboriginal or Torres Strait Islander council or organisation. Colloquially referred to as a 'Confirmation of Aboriginality' the supporting document is generally required in order to apply for scholarships and to work in identified positions and access services designed specifically for Aboriginal or Torres Strait Islander people. It is not a trivial or sentimental document; it is a quasi-legal document, which can be and is used to evidence claims of Indigeneity (Carlson 2016).

The three-pronged definition, however, does not always fit the multitude of experiences, relocations, and policy prescriptions that Aboriginal people have had to face under colonial conditions (see, Carlson 2016). Nyamai psychologist Dr Tracy Westerman made this clear in her Twitter posts:

Proof of Aboriginality keeps getting raised \& it angers me. It not only perpetuates the trauma of assimilation but places an onus of proof on Aboriginal ppl that we ask of no other culture. It affirms a mindset that openly questioning Aboriginality on the basis of skin tone is ok...

The requirement 2 "prove" indigenous identity is as emotional as it is increasingly politicised. As a psychologist all I see is the collateral damage created 4 indigenous people who as a direct result of assimilation policies cannot "prove" connection. It is so retraumatising. (@TracyWesterman, tweeted 15 January 2020)

While most who seek a formal Confirmation of Aboriginality document already identify and already know or have traced their family lineages, the issue of being recognised and accepted 'by the community in which he/she lives' can provide a stumbling block given the diasporic position of many Indigenous people. It should also be noted that possessing a Confirmation of Aboriginality document does not always shield the possessor from accusations of not being Indigenous. Nobody is exempt from being questioned as Wiradjuri author Anita Heiss explains: “In our own Aboriginal community, comments in discussions around who is and who is not Aboriginal can range from "They're not black enough" to accusing individuals of being "Johnny-come-lately's" (Heiss 2007, p. 51). Heiss also notes that "Criticism of Aboriginal people by Aboriginal people is strong, and no one escapes" (Heiss 2007, p. 53).

\section{Indigenous LGBTQI+ (Lesbian, Gay, Bisexual, Transgender, Queer, and Intersex) Identity}

Gender and sexually diverse peoples identify myriad struggles relating to the requirement to be accepted by an Indigenous community which often exclude them on the basis of non-normative sexual and gender identities. Dislocation and diaspora are common themes in Indigenous LGBTIQ+ critical writings (see, Day 2020; O'Sullivan 2019; Whittaker 2017; Lindsay-Ross 2014; Hodge 2015; Farrell 2020). Indigenous gender identities are complex and have been deeply impacted by colonisation and the forced indoctrination of Christianity. The notion of heterosexuality has become normalised as part of this process and is often assumed as an innate part of Indigenous cultures which precede the arrival of the British. 
Through the embedding of homophobia and transphobia, many LGBTIQ+ identified Aboriginal and Torres Strait Islander peoples have had to seek safety and integrity within their gendered and sexual identities outside of their family and community contexts. Kurnai/Gunai, Gunditjmara, Wiradjuri, and Yorta Yorta activist and writer Nayuka Gorrie (2019) notes that:

There were queers in my family, of course, but typically they removed themselves.

There was never outright rejection, just whispers and insinuations ... us queers have to protect ourselves ... this is a kind of death, a part of the soul cauterised to protect the rest. (p. 21)

Some of our participants spoke about the issues they had with trying to have their Indigenous identity confirmed by community members. One member stated that they had never been able to secure a confirmation document: "for trans people, it's really difficult as nobody remembers you where you grew up as you are no longer that person". Several of our participants spoke about having to leave their communities due to homophobia. As one participant outlined: "The chairperson is really against gays and every time I applied for a confirmation certificate I was denied even though they know who I am. My aunty used to be on that board so they know I am Aboriginal". Wodi Wodi Queer scholar Andrew Farrell comments:

Physical and emotional dislocation is a common narrative in current media representations of queer Indigenous experiences, in which Indigenous LGBTIQ+ peoples express fraught relationships with home. We frequently seek out safer queer and Indigenous spaces and undertake the process of physical relocation, often to urban centres. We also navigate relationships with local Indigenous communities while contending with spaces and places claimed by settler queer peoples. (Farrell 2020, n.p.)

\section{Community Recognition}

Given the Indigenous community is tasked with confirming claims of Indigeneity, one would assume that there is a consensus on what constitutes 'the community'. However, this is not the case. The notion of community in relation to Aboriginal and Torres Strait Islander peoples is complex. Kamilaroi/Uralarai researcher Frances Peters-Little suggests that government policies and community organisations have been largely "shaping 'who' and 'what' constitutes an Aboriginal community" (Peters-Little 2001, p. 198). While throughout colonial history new Indigenous communities emerged through enforced relocation and dislocation from ancestral Country, the axiom of 'the Indigenous community' has only become entrenched in popular discourse since the 1970s to streamline government funding to Indigenous people.

Many questions emerge at these discursive intersections as to what constitutes 'community', and therefore who can speak for, or confirm an individual's identity (Peters-Little 2001; Lamb 2007; Carlson 2016). In March 2012, The Weekend Australian Magazine featured an article titled, 'Not so Black and White' detailing Aboriginal man Dallas Scott's experience of applying for a Confirmation of Aboriginality certificate and subsequent denial (Overington 2012, p. 15). Scott states that he has identified as Aboriginal all his life but when he wanted to access a service specifically designated for Aboriginal people, he was asked to provide proof of his identity. Scott was shocked by the rejection of his application for a Confirmation of Aboriginality document claiming: "every time I walk out the door I'm Aboriginal, and suddenly I'm not" (Overington 2012, p. 15). Scott turned to Facebook and updated his status, "Dallas Scott ... is apparently not Aboriginal after all" (Overington 2012, p. 15).

\section{Being 'Openly Indigenous' on Social Media}

Across our various research projects, identity is always raised as a topic of importance in people's digital lives (Carlson and Frazer 2018b). Identifying as Indigenous online was not always a straightforward matter as we have discussed. Participants in our research 
often expressed mixed views about being 'openly Indigenous' on social media. Results from one of the online surveys we conducted on Indigenous identity on social media revealed that over half of the respondents indicated they had been intentionally selective with what they post in regard to their identity. There were many reasons for this.

The vast majority of respondents were selective because of the negative reactions that Indigeneity could provoke from some other social media users. Many had experienced forms of abuse or discrimination online. They explained they had been questioned over whether they were "really Indigenous", with other users drawing on stereotypical ideas of Indigeneity, particularly around skin colour. There were many examples of this: "apparently I'm not black enough for some. It's their problem not mine"; "I am not too open about my Indigenous background on social media sites because I am light-skinned and have found that people pass judgement and make assumptions about my entitlements"; "Non-Indigenous people [have questioned me] based on the fact that I don't look Aboriginal to them". For others, abuse stemming from racist stereotypes of Indigenous 'inferiority' or 'criminality' was a constant presence in their online interactions.

For these reasons, many participants found that they needed to make the decision not to openly identify for safety and self-preservation with one participant stating: "it's sometimes safer to not identify as Aboriginal due to discrimination/prejudices". While, on the one hand, social media facilitated the expression of new forms of Indigenous identities, on the other, 'identifying online' could also become a matter of jeopardising personal safety. As an interviewee explained: "If anyone identifies as Aboriginal by standing up for anything Aboriginal they can get slammed by lots of bigots and people who hate anything Aboriginal".

In one respect, the online survey results offered clear answers, with a majority of respondents (82\%) openly identifying as Aboriginal and/or Torres Strait Islander on social media. Moreover, $73 \%$ of respondents indicated they believed social media helped them express their Aboriginal and/or Torres Strait Islander identity. As one survey respondent explained: "My Aboriginality is the focal point of my identity both in society and online. Specifically on Facebook, my photos and page/groups and friends all highlight my Aboriginality".

A majority of our participants said they expressed their Indigenous identity through engaging in a range of online practices. Often this was achieved through openly asserting one's heritage or kin through their social media profiles-particularly on Facebook and Twitter, where users can provide details or a brief description of 'who they are', including their nation/clan or Country of birth. As one interviewee explained: "In my description on Twitter and Instagram I specifically state that I am an Aboriginal woman". Participants said they also expressed their identity through the content they shared through their profiles, such as news articles about Indigenous-specific events, topics, or issues. As one interview participant explained: "At different times I might change my photo to have an Aboriginal flag or Aboriginal style". In this way, their identity is expressed through practices and symbolism, rather than directly identifying. For instance, one survey respondent explained: "I can show people my Aboriginality through pictures without having to state it awkwardly". Others were sceptical that social media platforms are capable of expressing something like their identity, which they personally experience as deeply rich and complex. As a respondent explained: "I don't know if I can adequately express my Aboriginal identity in such a short word length".

More than simply allowing users to express a pre-existing identity, social media also facilitates the production of a new or strengthened sense of identity. As another interviewee explained: "In helping to connect up with others across the country, I do get to feel more connected with my own sense of identity. It doesn't operate by itself as an affirmation of identity, but it's certainly an interesting space for talking about identity". In these cases, social media can help form rather than just express identity.

\section{Harmful Content}

In contrast with the positive affordances of the Internet regarding the multitude of possibilities for Indigenous peoples to express their identity and continued collective survival of colonialism, there exists a considerable amount of negativity and harmful content 
on social media. Participants throughout these studies confirmed that they routinely faced negative content in the form of widespread racism. A respondent to our online survey noted that social media: "gives racism a platform and ... becomes a tool for people with not very good intentions". This is conceptualized by Matamoros-Ferández (2017) as "platformed racism', a form of racism that is derived from the culture of social media platforms.

Participants routinely identified anonymity as a major contributing factor to the frequency of harmful content they encountered on social media. The anonymity afforded to Internet users is closely linked to what Santana refers to as: "rampant and unchecked incivility" (Santana 2014, p. 29). As one participant noted: " . . because people believe they are [anonymous] it allows them to be inappropriate. It seems there is little ramifications to people being racist, bullying, or inappropriate so where is the accountability!". Santana's research confirms this position in finding that, "The ways people express themselves online is significantly dependent on whether their true identity is intact" (Santana 2014, p. 29).

Racism on social media, according to participants in our research, is on the rise. Results from the Kennedy survey indicated that $62 \%$ of Indigenous social media users encountered racism and harmful content daily over the course of the preceding six months (Kennedy 2020). One respondent described social media as: "a lot of non-Indigenous people posting racist material, refusing to engage in a proper and considered conversation". Another identified their frequent encounters with: "racist, bigoted content that's deliberately intended to hurt people". While often dismissed as content that can be easily 'switched off', the reach and impact of racism on social media are particularly troubling. One respondent going so far as to avoid sharing any personal or identifying information online: "because [their] family's lives have been threatened by non-Indigenous people".

Lateral violence is also a continued problem faced by Indigenous peoples on social media. According to Bailey, lateral violence refers to:

a set of behaviours enacted by individuals and/or communities which are damaging in nature (to both the party performing the behaviours and those they are directed toward) and often occurring within oppressed societies. (Bailey 2020, p. 1035)

Lateral violence is the internalisation of violent aspects of colonial ideology, most commonly, surrounding the wanton erasure of identity and culture and the redirecting of this violence at members of one's own community. In Australia, challenging the authenticity and legitimacy of Indigenous peoples is a well-founded mechanism aimed at reifying the colonial myth of terra nullius - that Indigenous people have no claim to the Australian continent.

Experiences of social media by Indigenous peoples are increasingly involving encounters with lateral violence. One respondent highlighted their discomfort in witnessing: "a lot of shaming for people who didn't grow up with culture or don't live like that, on country or don't have a close connection". The suggestion that Indigenous people not 'growing up with culture' would necessarily prohibit them from identifying as Aboriginal is a colonial tactic to erase Indigenous culture and peoples. Lateral violence encourages Indigenous peoples to turn on each other and break cultures and communities apart.

The danger is that social media, through increased visibility and permanence of comments, posts, images, audio, and video which exhibit harmful content, allows for such negativity to permeate Indigenous communities much more readily. Racism and negative content (particularly lateral violence) founded on the ideological principles of colonisation on social media is highly visible. This content is easily internalised by Indigenous and non-Indigenous peoples alike. A clear and present danger in Australia and colonised countries throughout the globe is that social media may strengthen the dominance of the coloniser(s) due to the efficiency with which negative and harmful content can be spread across communities. 


\section{Conclusions}

Contemporary struggles in relation to Indigenous identity emerge in the shadow of colonialism and occur primarily around questions of 'who' is Indigenous and 'what' are the characteristics that evidence and confirm any legitimate claim to 'be' an Indigenous person. It should be noted that colonisation has impacted different geographical locations in Australia in different ways. This is a large continent and colonisers began their violence in 1788 on the East coast. Indigenous populations in these areas have had to deal with the violence of colonialism for the longest period of time and as a result, we see larger populations of people with an ancestral lineage that includes settlers.

The lack of consensus about who is or what counts as evidence of Indigeneity is raised in the "whitestream" media and on social media constantly as a significant problem in Australia. Consensus about who should be tasked with confirming claims of Indigeneity is also a contentious issue. As this article has demonstrated, identity remains a fraught topic that is complicated by colonial dictates regarding skin colour as a primary marker of authentication. Settler commentators, politicians, and public figures alike continue to pass judgement regarding who Indigenous people are and can be. Social media platforms can facilitate ways to both support and subvert this preoccupation.

Indigenous people use online platforms for their own ends, for the reinforcement of selfhood, for identifying and being identified, and as a vehicle for humour and subversion. Future research will necessarily focus on the emerging affordances of digital technology and the ability for questions of identity to further permeate the daily lives of Indigenous peoples. It remains clear though, that Indigenous people, despite online vitriol and threats to safety, ultimately decide what Indigenous identity means.

Author Contributions: Writing—original draft, B.C.; Writing-review \& editing, T.K. All authors have read and agreed to the published version of the manuscript.

Funding: Some data included in this paper is from research that is supported by the Australian Research Council Discovery Indigenous, Project ID: IN130100036. Additional data is from research supported by Facebook.

Institutional Review Board Statement: Both of these projects abided by and embodied Indigenous and university ethical guidelines. The ARC funded projects were approved by university ethics committees: IN13010036, The University of Wollongong. The Facebook project was approved by Macquarie University HREC, 52020593212807.

Informed Consent Statement: Informed consent was obtained from all Indigenous peoples who participated in these studies.

Data Availability Statement: The data collected as part of these research project is not publicly available due to ethics reuirements.

Acknowledgments: The authors wish to acknowledge and thank the Aboriginal and Torres Strait Islander people who participated in our studies. Your contributions, experiences and anecdotes have enriched this area of research. Additionally, we would also like to thank the research assistants in each community who generously provided us with information on local cultural protocols. Our lives are enriched by being in community with you.

Conflicts of Interest: The authors declare no conflict of interest.

\section{References}

Alfred, Taiaiake, and Jeff Corntassel. 2005. Being Indigenous: Resurgences against contemporary colonialism. Government and Opposition 40: 597-614. [CrossRef]

Bailey, Kerry. 2020. Indigenous students: Resilient and empowered in the midst of racism and lateral violence. Ethnic and Racial Studies 43: 1032-51. [CrossRef]

Bell, David, and Barbara Kennedy. 2000. The Cybercultures Reader. London: Routledge.

Boladeras, Jean. 2002. It's Easier to Be black if You're Black: Issues of Aboriginality for Fair-Complexioned Nyungar People. Master's thesis, Curtin University of Technology, Perth, Australia. 
Bolt, Andrew. 2009. White Is the New Black. Herald Sun. April 15. Available online: https://www.heraldsun.com.au/blogs/andrewbolt/column---white-is-the-new-black/news-story/2d639a94bb361ca786b9b2c171a4da04 (accessed on 11 April 2021).

Bond, Chelsea. 2007. "When you're black, they look at you harder" Narrating Aboriginality within public health. Doctoral thesis, University of Queensland, Brisbane, Australia.

Brock, André, Jr. 2020. Distributed Blackness: African American Cybercultures. New York: NYU Press, vol. 9.

Butler, Judith. 2017. Who's Your Mob? Aboriginal Mapping: Beginning with the Strong Song. The International Journal of Therapy Work. 3. Available online: https://dulwichcentre.com.au/wp-content/uploads/2018/06/Whos-your-mob-by-Justin-Butler.pdf (accessed on 8 April 2021).

Carlson, Bronwyn. 2013. The 'new frontier': Emergent Indigenous identities and social media. In The Politics of Identity: Emerging Indigeneity. Edited by Harris Michelle, Martin Nakata and Bronwyn Carlson. Sydney: University of Technology Sydney E-Press, pp. 147-68.

Carlson, Bronwyn. 2016. The Politics of Identity: Who Counts as Aboriginal Today? Canberra: Aboriginal Studies Press.

Carlson, Bronwyn. 2020. Here Is the Truth about the 'free ride' That Some Think Indigenous People Get. SBS. Available online: https:/ / www.sbs.com.au/topics/voices/culture/article/2016/12/07/heres-truth-about-free-ride-some-australians-thinkindigenous-peoples-get (accessed on 10 April 2021).

Carlson, Bronwyn, and Ryan Frazer. 2018a. Cyberbullying and Indigenous Auséralians: A Review of the Literature. Sydney: Macquarie University, Available online: https:/ / research-management.mq.edu.au/ws/portalfiles / portal/92634728/MQU_Cyberbullying_ Report_Carlson_Frazer.pdf (accessed on 8 April 2021).

Carlson, Bronwyn, and Ryan Frazer. 2018b. Social Media Mob: Being Indigenous online. Sydney: Macquarie University, Available online: https:/ / researchers.mq.edu.au/en/publications/social-media-mob-being-indigenous-online (accessed on 10 April 2021).

Christensen, Neil Blair. 2003. Inuit in Cyberspace: Embedding Offline, Identities Online. Copenhagen: Museum Tusculanum Press.

Day, Madi. 2020. Indigenist Origins: Institutionalizing Indigenous Queer and Trans Studies in Australia. TSQ: Trans Studies Quarterly 7: 367-74. [CrossRef]

DeWitt, Courtney. 2015. We interviewed Australia's Warriors of the Aboriginal Resistance. Vice. Available online: https://www.vice. $\mathrm{com} / \mathrm{en} /$ article/7b7n3q/interview-with-the-warriors-of-aboriginal-resistance (accessed on 21 May 2021).

Duncan, Pearl. 2014. The Role of Aboriginal Humour in Cultural Survival and Resistance. Doctoral thesis, University of Queensland, Brisbane, Australia.

Farrell, Andrew. 2020. Queer and Aboriginal in a Regional Setting: Identity and Place. Archer. Available online: http://archermagazine. com.au/2020/06/queer-and-aboriginal-identity-and-place (accessed on 8 April 2021).

Ganter, Regina. 2008. Turning Aboriginal-Historical bents. Borderlands Ejournal 7: 1-19.

Gardiner-Garden, John. 2002-2003. Defining Aboriginality in Australia; Canberra: Department of Parliamentary Library. Available online: https:/ / www.aph.gov.au/about_parliament/parliamentary_departments/parliamentary_library/publications_archive/ cib / cib0203/03cib10 (accessed on 5 April 2021).

Gorrie, Nayuka. 2019. Rob, and Queer Family. In Growing up Queer in Australia. Edited by Law Benjamin. Carlton: Black Inc., pp. 21-24.

Gorringe, Scott, Joe Ross, and Cressida Forde. 2011. Our relationships in native title: Starting the conversation. Australian Institute of Aboriginal and Torres Strait Islander Studies 28: 1-23.

Han, Esther. 2019. "Everybody Hates a Welfare Rorter": Latham Spruiks DNA Testing Plan for Aboriginal People. Sydney Morning Herald. Available online: https://www.smh.com.au/politics/nsw/everybody-hates-a-welfare-rorter-latham-spruiks-dnatesting-plan-for-aboriginal-people-20190311-p513au.html (accessed on 8 April 2021).

Heiss, Anita. 2007. Writing Aboriginality: Authors on "being Aboriginal”. In A companion to Australian literature Since 1900. Edited by Birns Nicholas and Rebecca McNeer. New York: Camden House.

Hodge, Dino. 2015. Colouring the Rainbow: Blak Queer and Trans Perspectives: Life Stories and Essays by First Nations People of Australia. Adelaide: Wakefield Press.

Huggins, Jackie. 2003. Always was, always will be. In Blacklines: Contemporary Critical Writings by Indigenous Australians. Edited by Michele Grossman. Carlton: Melbourne University Press, pp. 60-65.

Johnson, Daniel Morley. 2011. From the tomahawk chop to the road block: Discourse savagism in whitestream media. American Indian Quarterly 35: 104-34. [CrossRef]

Kennedy, Tristan. 2020. Indigenous Peoples' Experiences of Harmful Content on Social Media. Sydney: Macquarie University. Available online: https:/ / research-management.mq.edu.au/ws/portalfiles/portal/135775224/MQU_HarmfulContentonSocialMedia_ report_201202.pdf (accessed on 8 April 2021).

Lamb, Natasha. 2007. Aboriginalising racism-Regional experiences of racism between Aboriginal groups. Paper presented at International Conference on Racism in the New World Order: Realities of Colour, Culture and Identity Conference, University of the Sunshine Coast, Queensland, Australia, December 8-9; pp. 177-83. Available online: http://www.usc.edu.au/nr/rdonlyres/ b48e9bb0-04ae-4d95-b710-512fd0973954/0/racismsconf3.pdf (accessed on 5 April 2021).

Liddle, Celeste. 2014. Why I Prefer the Term 'Black'. Daily Life. Available online: http:/ / www.dailylife.com.au/life-and-love/real-life/ why-i-prefer-the-term-black-20140224-33cte.html (accessed on 5 May 2021).

Lindsay-Ross, Steven. 2014. Homosexuality and Aboriginal Culture: A Lore Unto Themselves. Archer. June 2. Available online: http: //archermagazine.com.au/2014/10/homosexuality-and-aboriginal-culture-a-lore-unto-themselves/ (accessed on 8 April 2021). 
Lumby, Bronwyn. 2010. Cyber-Indigeneity: Urban Indigenous identity on Facebook. The Australian Journal of Indigenous Education 39: 68-75. [CrossRef]

Manne, Robert. 2010. Sorry Litinay of misinformation. The Australian. Available online: https:/ www.theaustralian.com.au/opinion/ sorry-litany-of-misinformation/news-story/87b1adc49047f73425e3a0ce5832b48f (accessed on 20 May 2021).

Mansell, Michael. 2014. Andrew Bolt, Indigenous Australian? Come off It. The Guardian. Available online: https://www.theguardian. com/commentisfree/2014/jan/31/andrew-bolt-indigenous-australian-come-off-it (accessed on 12 April 2021).

Martin, Karen. 2008. Please Knock before You Enter: Aboriginal Regulation of Outsiders and the Implications for Researchers. Brisbane: Post Press.

Matamoros-Ferández, Ariadna. 2017. Platformed racism: The mediation and circulation of an Australian race-based controversy on Twtter, Facebook and Youtube. Information, Communication and Society 20: 930-46. [CrossRef]

McCormick, Naomi, and John Leonard. 1996. Gender and Sexuality in the Cyberspace Frontier. Women and Therapy 19: 109-19. [CrossRef]

McCorquodale, John. 1986. The legal classification of race in Australia. Aboriginal History 10: 7-24. [CrossRef]

McCorquodale, John. 1997. Aboriginal identity: Legislative, judicial and administrative definitions. Australian Aboriginal Studies 2: 24-35.

Moreton-Robinson, Aileen. 2013. Towards an Australian Indigenous women's standpoint theory: A methodological tool. Australian Feminist Studies 28: 331-47. [CrossRef]

Nakata, Martin. 2007. Disciplining the Savages, Savaging the Disciplines. Canberra: Aboriginal Studies Press.

Noble, Fiona. 1996. Who do we Think we are: People who are Learning About their Aboriginality. Masters thesis, Griffith University, Queenland, QLD, Australia.

O'Sullivan, Sandy. 2019. A Lived Experience of Aboriginal Knowledges and Perspectives: How Cultural Wisdom Saved My Life. In Practice Wisdom. Edited by Higgs Joy. Leiden: Brill Sense, pp. 107-12.

Overington, Caroline. 2012. Not so Black and White. Weekend Australian Magazine, March 24-25.

Oxenham, Darlene, Jo Cameron, Kim Collard, Pat Dudgeon, Darren Garvey, Marion Kickett, Tracey Kickett, Jennie Roberts, and Jules Whiteway. 1999. A Dialogue on Indigenous Identity: Warts ' $n$ ' All. Perth: Gunada Press.

Paradies, Yin. 2006. Beyond black and white: Essentialism, hybridity and indigeneity. Journal of Sociology 42: 355-67. [CrossRef]

Peters-Little, Frances. 2001. The community game: Aboriginal self definition at the local level. The Indigenous Welfare Economy and the CDEP Scheme 20: 187.

Racial Discrimination Act. 1975. Available online: https:/ / www.legislation.gov.au/Details/C2016C00089 (accessed on 20 May 2021).

Rigney, Lester. 1997. Internationalization of an Indigenous Anticolonial Cultural Critique of Research Methodologies: A Guide to Indigenist Research Methodology and Its Principles. Wicazo SA Review 14: 109-21. [CrossRef]

Robins, Kevin. 1995. Cyberspace and the world we live in. Body E Society 1: 135-55.

Santana, Arther. 2014. Virtuous or vitriolic: The effect of anonymity on civility in online newspaper reader comment boards. Journalism Practice 8: 18-33. [CrossRef]

Sardá, Thias, Simone Natale, Nikos Sotirakopoulos, and Mark Monaghan. 2019. Understanding online anonymity. Media, Culture $\mathcal{E}$ Society 41: 557-64.

Shapiro, Eve. 2015. Gender Circuits, 2nd ed. New York: Routledge.

Smith, Linda Tuiwai. 2012. Decolonizing Methodologies: Research and Indigenous Peoples, 2nd ed. London: Zed Books.

Stanner, William Edward Hanley. 1979. Whiteman Got no Dreaming: Essays 1938-1973. Canberra: Australian National University Press.

Whittaker, Alison. 2017. Queerness and Indigenous Cultures: One World, Many Lives. Archer. January 6. Available online: https: / / archermagazine.com.au/2016/08/queerness-indigenous-cultures/ (accessed on 11 April 2021).

Yahoo News. 2019. I'm Indigenous': Pauline Hanson's Cringeworthy Confrontation. Available online: https:/ /au.sports.yahoo.com/ pauline-hanson-confrontation-with-indigenous-girls-uluru-rock-climb-closure-nt-141411729.html (accessed on 12 April 2021). 